\title{
Numerical and Response Surface Interactions for Optimizing Extrusion Parameters
}

\author{
Gundu David Terfa ${ }^{1,}$, , Tuleun Livinus Tyovenda ${ }^{1}$, Agber Jonathan Uhaa ${ }^{2}$ \\ ${ }^{1}$ Department of Mechanical Engineering, University of Agriculture, Makurdi, Nigeria \\ ${ }^{2}$ Department of Electrical/Electronics Engineering, University of Agriculture, Makurdi, Nigeria
}

Email address:

dtergundu@yahoo.com (D. T. Gundu),dterfa.gundu@uam.edu.ng (D. T. Gundu)

\section{To cite this article:}

Gundu David Terfa, Tuleun Livinus Tyovenda, Agber Jonathan Uhaa. Numerical and Response Surface Interactions for Optimizing Extrusion Parameters. International Journal of Materials Science and Applications. Vol. 4, No. 3, 2015, pp. 143-148.

doi: $10.11648 /$ j.ijmsa.20150403.11

\begin{abstract}
An experimental program was undertaken to extrude a lead alloy on ELECompact-1500 compression machine. Extrusion variables were extrude diameter (d), die bearing length (h), and included die entrant angle $\Theta=90^{\circ}$. Using experimental values, numerical models were obtained to describe the relationship between extrusion variables and extrusion pressure and extrude deflection. The numerical models were then used to obtain the response pressure predictions for aluminum alloy. Results of validation tests indicated good correlation between predicted and experimental values. The predictions also compare favorably with values obtained by a similar second-order modified upper bound model frequently used in industry for estimating extrusion loads with prediction errors below 4\%. Surface responses graphs of extrusion pressure and extrude deflection were also used to define the optimized field for interaction of extrusion parameters for minimizing extrusion loads and controlling extrudes deflection or bending. Owing to fewer input variables, the proposed models were considered convenient options for a quick estimate of extrusion loads and product curvature.
\end{abstract}

Keywords: Numerical Models, Response Surface, Optimizing, Extrusion, Die Pressure, Extrude Deflection

\section{Introduction}

Extrusion is one of the forming techniques used in materials processing. The term is usually applied to both the process, and the product obtained when a cylindrical work piece or billet is pushed through a shaped die, thereby reducing its cross-section [1]. The extrusion process is made up of many variables such as alloy composition, temperature, tooling, and profile configuration. Many of these variables can be controlled fairly easily, but some cannot. However, all aspects of the extrusion process have to work within the tightest possible parameters to obtain the desired outcome [2]. The extrusion produces large deformations which affect the mechanical properties of finished product, impacting the material's crystallographic texture morphology and residual stresses. Thus, the product's final characteristics are dependent upon the complex interaction of the alloy system, thermal and mechanical processing steps (billet temperature, extrusion speed, product cross-section, extrusion and final heat treatment, stretch straightening, etc). Extrusion processes therefore require a high degree of control of the thermo-mechanical conditions in relation to their effect on the final mechanical properties [3]. Combining process and material property prediction models has shown improvement in the consistency [4]; [5] and fundamental performance of extrusion operations, finishing steps and higher material yields.

Much attention has been given to the study of the die bearing area because it has dominant influence on the characteristics of extrusion process. Several studies have established that the geometry and shape of the die bearing area have significant effect on extrusion load, balance flow and product quality [6] - [9]. One of the greatest challenges in the design of an actual extrusion operation is obtaining realistic manufacturing process parameters to plant execution. Conventional finite element analysis and other numerical methods been applied to extrusion processes. However, these do not consider the manufacturing constraints in their modeling and hence, the process parameters obtained through such analysis were more theoretical and not realistic enough [10]. Modeling of material flow through extrusion tool requires the prediction of unknown quantities such as extrusion pressure, flow velocity and temperature [11], and the 
performance of numerical evaluations in predicting extrusion parameters have been reported by many researchers [12]. Numerical simulations have been used successfully to obtain optimum process parameters and to improve die bearing geometry and design of specific dies to achieve uniform exit velocity of profiles [13] - [18]. The relationship between dependent and independent extrusion process parameters most commonly takes either polynomial or exponential trends; studies have also shown that second-order polynomial models and the modified upper bound model equation (3) were found to accurately describe the relationship between extrusion parameters, and are frequently used in industrial environment to estimate maximum extrusion force (or pressure) for conical die bearings [19] - [22]. However, owing to large input variables, estimating extrusion parameters requires several tasking computations and this is not convenient especially where computational infrastructure is not available.

The objective of the present study was to develop using experimental values convenient 3 -d numerical models, and to show the use of surface responses approach for optimizing the interactions between extrusion parameters.

\section{Materials and Methods}

\subsection{Preparation of Extrusion Billets}

Lead alloy with approximate composition $67 \% \mathrm{~Pb}$, $26.5 \% \mathrm{Sn}$, and $6.5 \% \mathrm{Bi}$ obtained from automobile battery grids and terminals was melted and cast in galvanized steel moulds. The casts were machined into extrusion test billets to dimensions $\varnothing 25.4 \mathrm{~mm}$ by $26.0 \mathrm{~mm}$.

\subsection{Extrusion Procedure}

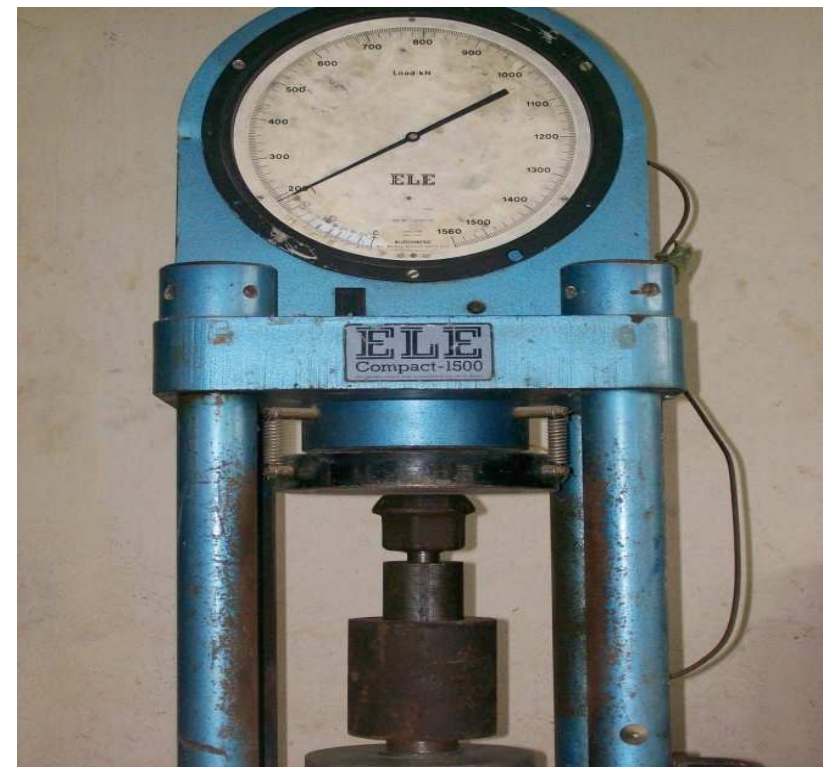

Figure 1. Extrusion Setup

Extrusion billets were directly extruded on manual ELE Compact-1500 hydraulic compression testing machine as shown on Figure 1. Lubrication was not considered necessary, and average values of maximum extrusion loads were obtained for each extrusion at the steady stage of the process as in [23].

\subsection{Extrude Deflections}

Extrudes were carefully separated from the dies and were held on lathe machine using three-jaw chuck. By rotating the chuck, axial deflections were measured at $25 \mathrm{~mm}$ from the chuck face as shown on Figure 2. using a high sensitivity (0.001) vertical height gauge.

\subsection{Model Validation}

By interpolation and extrapolation of experimental data and empirical 2-D models, 3D numerical models for predicting extrusion pressure equation (1) and extrudes deflection equation (2) were obtained [8], [23].

$$
\begin{gathered}
p(d, h)=C \mu \sigma_{f} e^{n(h-d)} \\
\delta(d, h)=\delta_{0} e^{-n(d+h)} \\
P=2 \sigma_{f}\left[4 \mu\left(\frac{H}{D}+\frac{h}{d}\right)+\left(\frac{1}{\theta}+\frac{1}{\sqrt{3}}\right) \ln \frac{D^{2}}{d^{2}}\right]
\end{gathered}
$$

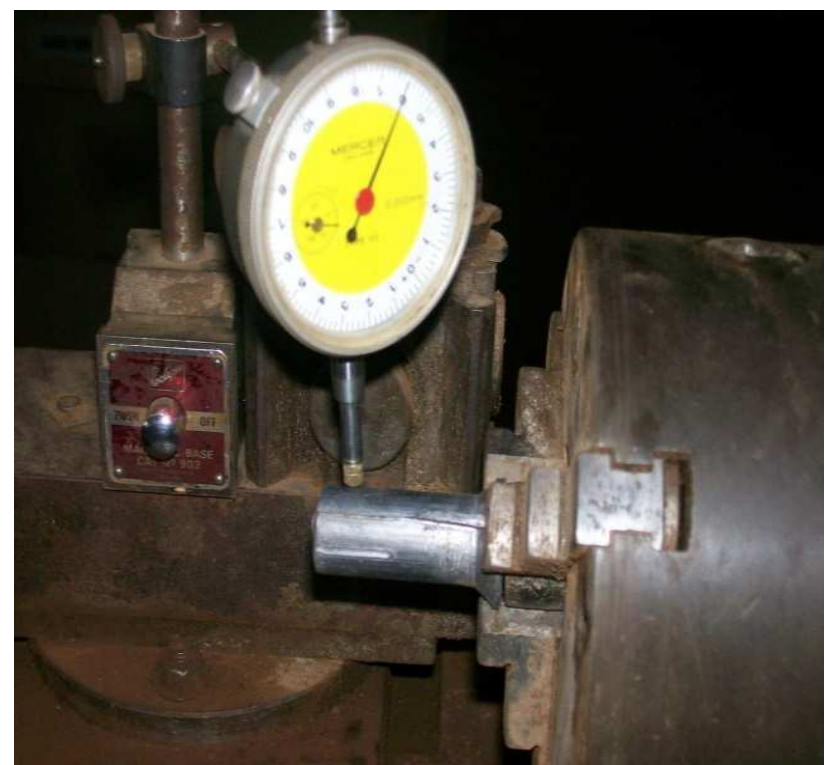

Figure 2. Experimental setup for extrude deflections

Where $d$ is die diameter, $h$ is the die bearing length, $\mu$ is the coefficient of friction, $\sigma_{f}$ is the yield (flow) stress of the aluminum alloy material, $C$ and $n$ are material constants; $\delta_{0}$ represents the extrude deflection for a die profile with zero die diameter and zero bearing length (imaginary knife-edged bearing); $\mathrm{H}, \mathrm{D}, \theta$ are respectively billet height, billet diameter, and die angle. Equations (1) and (2) were then simulated to obtain predictions of extrusion pressure at various die bearing lengths and die diameters, and the predicted values were compared with values obtained using the industrial model equation (3) reported in [21]. Material and other parameters used in the simulations are given in Table 1. Validation of the developed numerical models was carried out using correlation coefficient (R), mean absolute error (MAE), root means 
square error (RMSE), Nash-Scutcliffe efficiency (NSE) [24], platform.

[25]. Response surface plots were generated on MATLAB

Table 1. Material and other parameters for simulations.

\begin{tabular}{llllllll}
\hline \multicolumn{2}{l}{ Billet dimensions } & Die exit angle & \multicolumn{7}{l}{ Constants } \\
\hline $\mathbf{H}$ & $\mathbf{D}$ & $\boldsymbol{\theta}$ & $\mathbf{C}$ & $\boldsymbol{\delta}_{\mathbf{0}}$ & $\boldsymbol{\mu}$ & $\boldsymbol{\sigma}_{\mathbf{f}}, \mathbf{M P a}$ & $\mathbf{n}$ \\
\hline 26 & 25.4 & $45^{\circ}$ & 18.57 & 0.518 & 0.5 & 185 & 0.03 \\
\hline
\end{tabular}

\section{Results and Discussion}

\subsection{Model Validation}

The results of validation tests (Table 2) for the developed 3D model equation (1) show that model predictions of extrusion pressure were in good agreement with experimental values as high correlation coefficients $(\mathrm{R} \approx 1$ and $\mathrm{NSE} \approx 1)$ were observed. Values of statistical indicators of MAE and RMSE also indicated minimal prediction errors. Similarly, results (Table 3 ) of validation test for the extrude deflection model also gave correlation coefficients $(\mathrm{R} \approx 1.0$ and $\mathrm{NSE} \approx 1.0$, and prediction error was estimated to be $5.93 \%$. Under ideal conditions the best-fit between predicted and measured values would yield $\mathrm{MAE}=0, \mathrm{RMSE}=0, \mathrm{R}=1$ and NSE $=1$ [25].

Table 2. Results of validation test for extrusion pressure model equation (2).

\begin{tabular}{|c|c|c|c|c|c|c|c|c|}
\hline \multirow{2}{*}{$\begin{array}{l}\text { Experiment } \\
\text { No }\end{array}$} & \multicolumn{2}{|c|}{ Parameters } & \multicolumn{6}{|c|}{ Pressure (MPa) } \\
\hline & $\mathrm{d}(\mathrm{mm})$ & $\mathbf{h}(\mathbf{m m})$ & Measured & Predicted & $\mathbf{R}$ & MAE & RMSE & NSE \\
\hline 1 & 11.5 & 1 & 1243.35 & 1240.48 & 1.000 & -0.191 & 0.741 & 0.997 \\
\hline 2 & 11.5 & 2 & 1278.81 & 1279.54 & 1.000 & 0.049 & 0.188 & 0.998 \\
\hline 3 & 11.5 & 8 & 1547.15 & 1541.68 & 1.000 & -0.298 & 1.154 & 1.000 \\
\hline 4 & 14 & 1 & 1148.77 & 1147.98 & 1.000 & -0.053 & 0.203 & 1.000 \\
\hline 5 & 14 & 2 & 1184.96 & 1184.12 & 1.000 & -0.056 & 0.216 & 1.000 \\
\hline 6 & 14 & 5 & 1300.46 & 1299.53 & 1.000 & -0.062 & 0.240 & 1.000 \\
\hline 7 & 14 & 8 & 1427.16 & 1426.18 & 1.000 & -0.065 & 0.253 & 1.000 \\
\hline 8 & 14 & 10 & 1518.44 & 1517.40 & 1.000 & -0.069 & 0.269 & 1.000 \\
\hline 9 & 16 & 8 & 1349.91 & 1340.44 & 1.000 & -0.631 & 2.445 & 0.968 \\
\hline 10 & 16 & 10 & 1432.02 & 1426.18 & 1.000 & -0.365 & 1.415 & 0.998 \\
\hline 11 & 17.5 & 8 & 1278.81 & 1279.54 & 1.000 & 0.049 & 0.188 & 0.998 \\
\hline 12 & 17.5 & 10 & 1349.91 & 1361.91 & 1.000 & 0.800 & 3.098 & 0.948 \\
\hline 13 & 20 & 2 & 981.47 & 983.14 & 1.000 & 0.111 & 0.431 & 1.000 \\
\hline 14 & 20 & 8 & 1176.32 & 1184.12 & 0.999 & 0.525 & 2.035 & 0.996 \\
\hline 15 & 20 & 10 & 1248.54 & 1259.86 & 0.999 & 0.769 & 2.980 & 0.943 \\
\hline
\end{tabular}

Table 3. Results of validation test for extrude deflection model equation (3).

\begin{tabular}{|c|c|c|c|c|c|c|c|c|}
\hline \multirow{2}{*}{$\begin{array}{l}\text { Experiment } \\
\text { No. }\end{array}$} & \multicolumn{2}{|c|}{ Parameters } & \multicolumn{6}{|c|}{ Extrude Deflection, mm } \\
\hline & $\mathrm{d}(\mathrm{mm})$ & $\mathbf{h}(\mathbf{m m})$ & Measured & Predicted & $\mathbf{R}$ & MAE & RMSE & NSE \\
\hline 1 & 11.5 & 1 & 0.378 & 0.356 & 1.000 & 0.001 & 0.006 & 0.999 \\
\hline 2 & 11.5 & 2 & 0.361 & 0.346 & 1.000 & 0.001 & 0.004 & 0.999 \\
\hline 3 & 11.5 & 5 & 0.325 & 0.316 & 0.988 & 0.001 & 0.002 & 1.000 \\
\hline 4 & 11.5 & 8 & 0.282 & 0.289 & 0.998 & -0.0004 & -0.002 & 1.000 \\
\hline 5 & 11.5 & 10 & 0.265 & 0.272 & 0.989 & -0.0004 & -0.002 & 1.000 \\
\hline 6 & 16 & 2 & 0.305 & 0.302 & 1.000 & 0.0002 & 0.001 & 1.000 \\
\hline 7 & 16 & 5 & 0.282 & 0.276 & 1.000 & 0.0004 & 0.002 & 1.000 \\
\hline 8 & 16 & 10 & 0.242 & 0.240 & 1.000 & 0.0001 & 0.001 & 1.000 \\
\hline 9 & 17.5 & 1 & 0.301 & 0.297 & 1.000 & 0.0002 & 0.001 & 1.000 \\
\hline 10 & 17.5 & 8 & 0.242 & 0.241 & 1.000 & 0.001 & 0.000 & 1.000 \\
\hline 11 & 17.5 & 10 & 0.228 & 0.230 & 1.000 & -0.0001 & -0.001 & 1.000 \\
\hline 12 & 20 & 1 & 0.282 & 0.276 & 0.995 & 0.0004 & 0.002 & 1.000 \\
\hline 13 & 20 & 2 & 0.261 & 0.268 & 1.000 & -0.0004 & -0.002 & 1.000 \\
\hline 14 & 20 & 5 & 0.245 & 0.245 & 1.000 & 0.0000 & 0.000 & 1.000 \\
\hline 15 & 20 & 8 & 0.226 & 0.224 & 1.000 & 0.0001 & 0.001 & 1.000 \\
\hline 16 & 20 & 10 & 0.205 & 0.210 & 1.000 & 0.0003 & -0.001 & 1.000 \\
\hline
\end{tabular}




\subsection{Model Comparison}

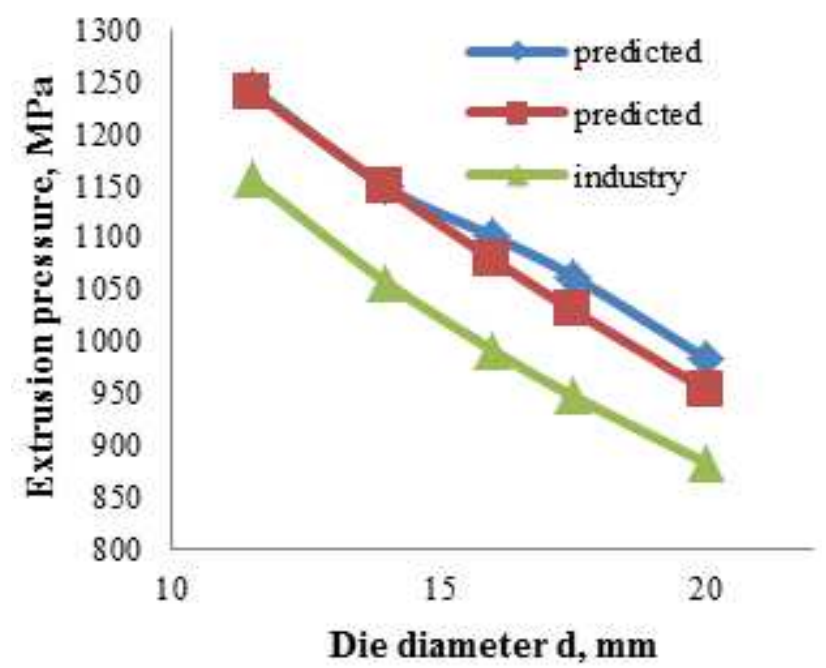

Figure 3. Response graph of extrusion pressure based on die diameter $d$ $(h=1.0 \mathrm{~mm})$

The comparison between experimental, predicted, and industry model equation (3) values are presented on the response surface graphs of extrusion pressure based on parameters d, h. Figure 3 indicates that extrusion pressure decreased as die diameter is increased and good correlation between experimental values and model predictions of extrusion pressure, and that model predictions are higher than values obtained using the industry model equation (3) reported in [21]. Figure 4 indicates that extrusion pressure increased as die bearing length is increased, and though the slopes of the two models are different, both model predictions show good correlation with experimental values. Similarly, Figure 5 and Figure 6 indicate that extrude deflection reduced as die diameter and die bearing length are increased.

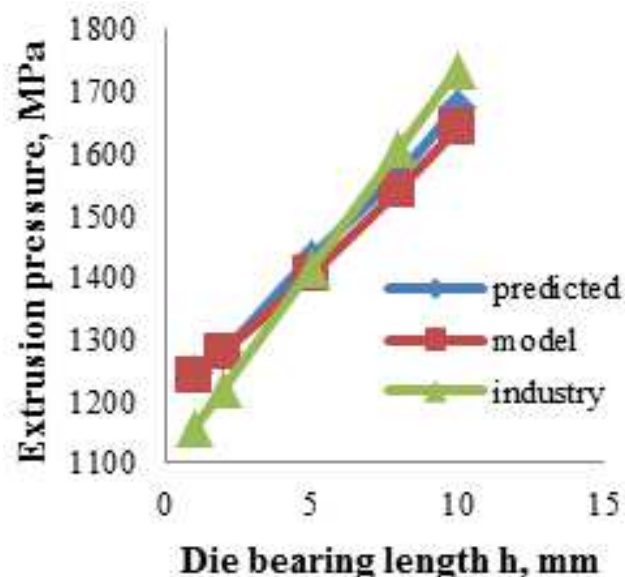

Figure 4. Response graph of extrusion pressure based on die bearing length $h$ $(d=11.5 \mathrm{~mm})$

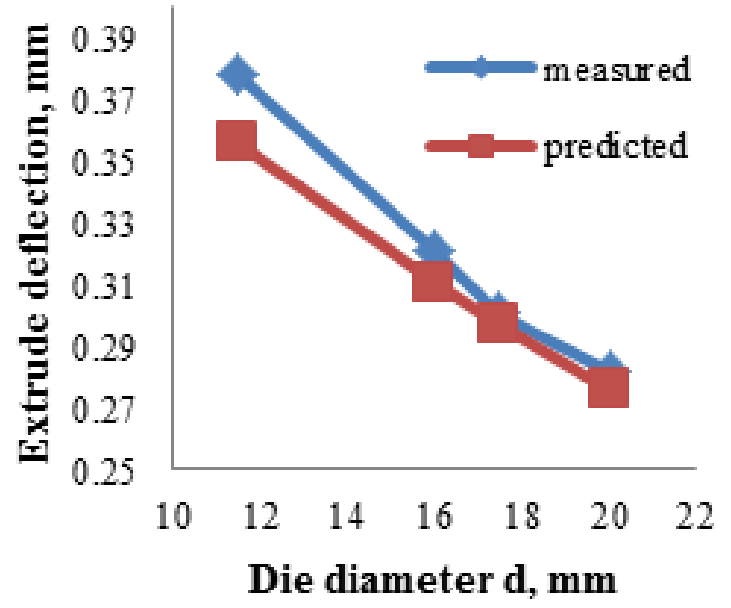

Figure 5. Response graph of ectrudes deflection based on die diameter $d$ $(h=1.0 \mathrm{~mm})$

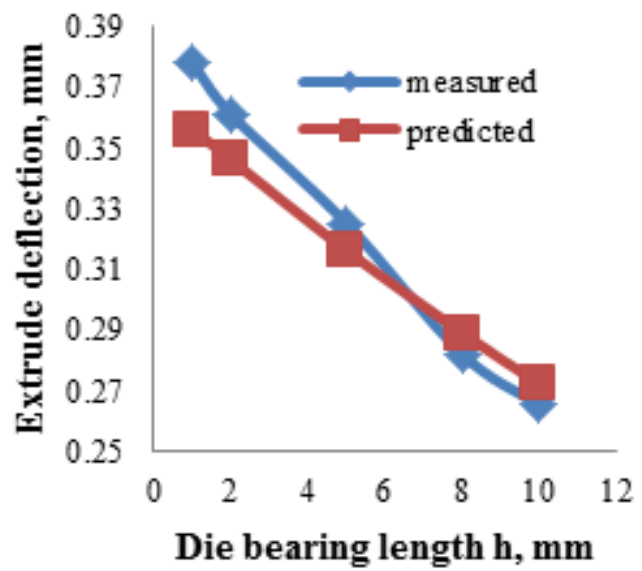

Figure 6. Response graph of extrudes deflection based on die bearing length $h(d=11.5 \mathrm{~mm})$

\subsection{Response Surface Interactions}

The responses surface graphs of extrusion pressure and extrude deflection (Figure 7 and Figure 8 ) show both 2D and $3 \mathrm{D}$ dimensional space of the interactions of the parameters $\mathrm{d}$, $\mathrm{h}$. The interactions between these parameters are described by two surfaces or boundaries which define upper and lower limits of the dependent variables thereby defining the optimized field for interaction of extrusion parameters for minimizing extrusion loads and also controlling extrude deflection or bending [20, 21]. Using numerical approaches, optimal values of extrusion parameters would require solving equations (1) and (3) simultaneously though laborious calculations. The response surface graphs also indicate the unpredictability of extrusion parameters with zero values of die diameter and die bearing length. 


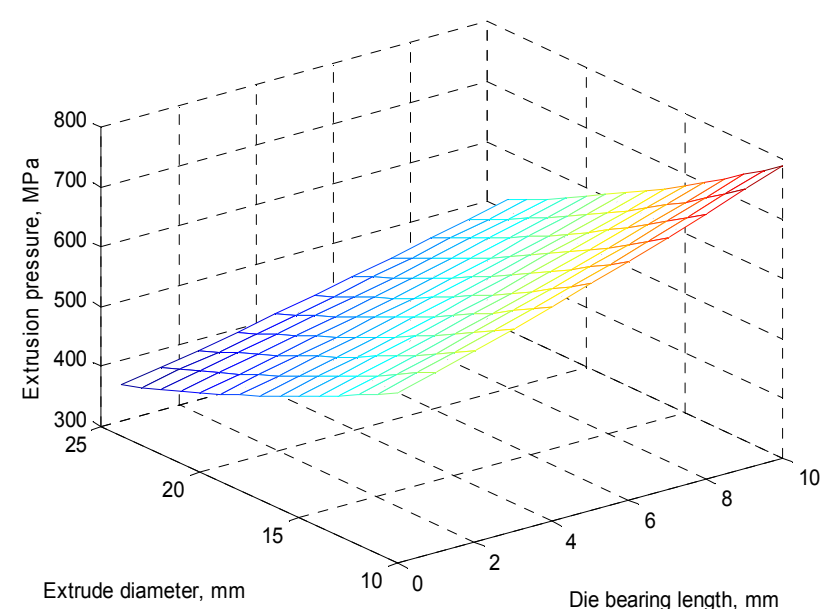

Figure 7. Response surface graph of extrusion pressure based on parameters $d, h$.

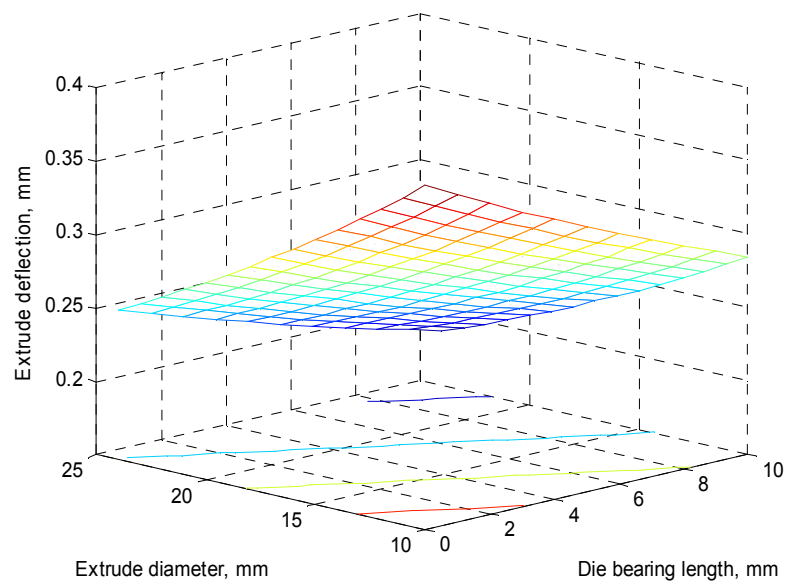

Figure 8. Response surface graph of extrude deflections based on parameters $d, h$.

\section{Conclusion}

Using the $90^{\circ}$ conical pocket die with parallel bearing achieved effective flow control, resulting in reduced extrusion pressure and extrudes deflections. Owing to fewer inputs, the proposed model equation (1) is considered more convenient for quick estimate of extrusion loads. The surface response plots also provide a good framework for visualizing interactions between extrusion parameters, and for optimizing die design to achieve minimized extrusion loads and control product bending.

\section{References}

[1] Chakrabarty, J.. Theory of plasticity. Int. Ed, McGraw-Hill, Inc., Singapore, 1987, 791p.

[2] Dion, G. "Achieving extrusion excellence and increasing profitability through process analysis," Aluminium Extrusion, 8(2): 30-32, 2003.

[3] Qamar, S.Z., Sheikh, A.K., Arif, A.F.M., Pervez, T., Siddiqui, R.A. "Heat treatment of a hot work die steel," Archives of Mater. Sci \& Eng., 28(8): 503-508. 2007
[4] Harris, C., Li, Q., Jolly, M.R. "Prediction of extruded microstructures using experimental and numerical modeling techniques," in Aluminium Two Thousand, $5^{\text {th }}$ World Congress, Rome, 31-35. 2003.

[5] Clode, M.P. and Sheppard, T. "Formation of die lines during the extrusion of AA6063," Mat. Sci. \& Tech., 6: 755-763. 1990.

[6] Onuh, S.O., Ekoja, M., Adeyemi, M.B. "Effects of die geometry and extrusion speed on cold extrusion of aluminium and lead alloys," J. Mater. Proc. Tech., 132: 274-285. 2003.

[7] Kawalek, A., Milenin, A. Dyja, H. (2005). "Analysis of the effect of die shape on the state of strain in the process of extrusion of thin-walled aluminium sections," Metallurgija, 44(2): $97-101$.

[8] T. Gundu, L. Tuleun, O. Injor (2014). "Experimental investigations on the effects of pocket die bearing geometry on extrusion pressure and bending," American Journal of Mechanical Engineering, 2014, 2(3): 65-69.

[9] Carmai, S.J.J, Pitakthapanaphong, S., Sechjarern (2008). “3D finite element analysis of metal flow in hot aluminium extrusion of T-shaped profile with various offset pockets," $J$. Achievements in Mater. and Manuf. Eng., 31(2): 463-468.

[10] Bajimaya, S.M., Park, S.C., Wang, G.N. (2007). "Predicting extrusion process parameters using artificial neural networks,".Int. J. Mech. Sys. Sci. \& Eng. 1(3): 161-165.

[11] Bourqui, B.C., Brunetti, A., Kahenbuhl, Y, S. (2002). "Integration of 3-D finite element flow modeling in extrusion tool conception and fabrication,". Development Project Report Commission pour la Technologie et l'Innovation, www.m-td .com/101_DD179.pdf.

[12] Narooei, A. and Karimi-Taheri, A. (2010). "A new model for the predicting the strain field and extrusion pressure in ECAE process of circular cross section," Applied Math. Model. 34: 1901-1917.

[13] Ulysse, P. "Optimal extrusion die design to achieveflow balance," Int. J. Machine Tools \& Manuf., 39: 1049-1064. 1999.

[14] Byon, S.M., Hwang, S.M. "Die shape optimal design in cold and hot extrusion," J. Mater. Proc. Tech. 138: 316-324. 2003.

[15] Lof, J. "Elasto-viscoplastic FEM simulations of the aluminium flow in the die bearing area for extrusion of thin-walled sections," J. Mater. Proc. Tech. 114: 174-183. 2001.

[16] Golovko, O., Mamuzic, I., Grydin, O. (2006). "Method for pocket die design on the basis of numerical investigations of aluminium extrusion process," Metallurgija 45(3): 155-161.

[17] Noorani, A.M., Bakshi, J.M., Hosseinipour, S.J., Gorji, A. (2005). "Experimental and numerical study of optimal die profile in cold forward rod extrusion of aluminium," J. Mater. Proc. Tech. 164-165: 1623-1632.

[18] Yan, H. and Xia, J. (2006). "An approach to the optimal design of technological parameters in the profile extrusion process," Sci. \& Tech. Adv. Mater. 7:127-131.

[19] Draganescu, F., Draganescu, B., Iliescu, M. (2002). "Statistic modeling of the maximum and average force coefficient in punching," Poly. Univ. Lasi Bulletin, 37-40. 
[20] Sahoo, A.K., Rout, A.K. (2009). "Investigation of optimal parametric combination for minimum cutting force in turning: response surface methodology approach," J. Eng. Innovation Res. 1: 6-13.

[21] Tiernan, P., Draganescu, B., Hillery, M.T., (2005). "Modeling of extrusion force using the surface response method," Int. $J$. Manuf. Tech. 27: 48-52.

[22] Jurkovic, Z., Jurkovic, M., Buljan, S. (2006). "Optimization of extrusion force prediction model using different techniques," $J$. Achieve. Mater. Manuf. Eng. 17:353-356.
[23] Gundu, D.T. "Investigations and numerical modeling of material flow in forward extrusion using pocket die bearings," Doctoral dissertation, University of Agriculture, Makurdi-Nigeria, 2010.

[24] Haghadadi, N., Zarei-Hanzaki, A., Khalesian, A.R., and Abedi, H.R. (2013). "Artificial neural modeling to predict the hot deformation behavior of an A356 aluminium alloy," Materials \& Design.49: 386.

[25] Mohanty, S., Madan Kjha, Ashawani K., Panda D.K. (2013). "Comparative evaluation of numerical model and artificial neural network for simulating groundwater flow in Kathajodi-Surua inter-basin of Odisha," Indian J. Hydrology, 495: 38-51. 